\title{
THE AQUATIC-POLYCARBONATE SKYLIGHT FOR SURABAYA- INDONESIA
}

\author{
Danny Santoso Mintorogo \\ Sustainable Architectural Science Studies Laboratory \& Department of Architecture, Petra Christian University, \\ Surabaya, Indonesia \\ Email: dannysm@ @eter.petra.ac.id
}

\begin{abstract}
This paper will indicate of how appropriate use of aquatic skylight module installed on buildings in the tropical zone compared to the ones in the subtropical climate. In order for energy saving strategies, the aquatic-polycarbonate skylight system is used in the tropical climate. In the tropical hot humid climate, Indonesia has received huge amount of global direct and diffuse radiations on horizontal roofs throughout the year, approximately 525 watts per square meter of solar radiation will impact on flat roofs or skylights on a clear sunny day in Surabaya city. Ironically, most of the commercial and institution buildings are equipped with Western skylight styles in Surabaya without any modifications. The aquatic-polycarbonate skylight is the system that will control daylight, scatter direct solar heat radiation, cool the indoor polycarbonate surface temperature, and collect solar hot water at the same time. The concept of using the water as shading device has three goals: first of all, the flushing water in the polycarbonate holes tries to scatter horizontal or tiled skylight direct sun-ray radiation, and minimize the direct sun heat temperature on the polycarbonate with flushing water continuously. Secondly, the sparkle flushing water in series of square holes of polycarbonate will bounce and disperse the direct sunlight into the space below enhancing daylight patterns. Finally, while bouncing, sparkling and scattering direct sunlight, those series of flushing water holes would also collect the solar heat radiation as solar hot water. Each system could works nicely to absorb, to scatter, to minimize, and to obtain the solar heat radiation for solar hot water in buildings. This strategy aims to provide a clean environment living zones with applying passive heating and cooling systems.
\end{abstract}

Keywords: Aquatic-Skylight, polycarbonate.

\section{FOREWORD}

A well-established priority in designing skylight for tropical humid climate deal with both the needs of the Daylighting to support the building activities and the needs to minimize direct solar heat radiation on cooling loads that will lead to the energy consumption as practically low as possible throughout the life of the buildings yearly. The earth gaining heat mostly comes from the sun, the direct sunlight beam that carries the infrared red, the ultra violet, and the visible lights. The infrared red and ultra violet waves become the solar heat radiation when striking on any surface under the sky. Based on Szokolay (1992), the amount of $24 \%$ of the solar radiation reaches the ground level as direct beam radiation, $22 \%$ is diffuse radiation, and $23 \%$ is absorbed in the atmosphere.

Indonesia with the tropical humid climate is situates at the latitude ranging from $6^{\circ} 8^{\prime}$ North to latitude $11^{\circ} 15^{\prime}$ 'South and the longitude ranging from $94^{\circ} 45^{\prime}$ East to $141^{\circ} 5^{\prime}$ East. The wet rainy season is approximately from mid December to mid May. Meanwhile, the hot humid season starts from mid May to mid December. The Surabaya city is located at the latitude $7^{\circ} 17^{\prime}$ to the South and at the longitude $112^{\circ} 47^{\prime}$ to the East. And Surabaya experiences quite a high percentage of sunshine condition throughout the day and the year, even during the rainy season. With the data which have been taken from the Surabaya Bureau of Meteorology at three stations, such as Perak 1, Perak 2 (harbor location), and Juanda (airport location), figure 1 shows the monthly average sunshine duration for the years of 1996 to 2002. During the dry season which is from May to October, the monthly average sunshine duration percentage is surprisingly high. The sunshine duration ranges from above $80 \%$ to $95 \%$ throughout the days and months. Even during the rainy season from the month of November to the month of April, the average sunshine duration is still above 50\%. These phenomena indicate that Surabaya city is obviously an excellent means to come up to passive daylighting all the time to either commercial, offices, institution buildings or dwellings for saving energies, reducing electric lights and applying solar photovoltaic powers during the working hours. Conversely, due to improper skylights installed in Indonesia, the cooling loads on most air conditioned buildings and dwellings will increase significantly. Surabaya with the $7^{\circ} 17^{\prime}$ latitude that is close to the equator will receive global direct and diffuse solar radiation from all directions every time which is greater on horizontal than inclined surfaces. 


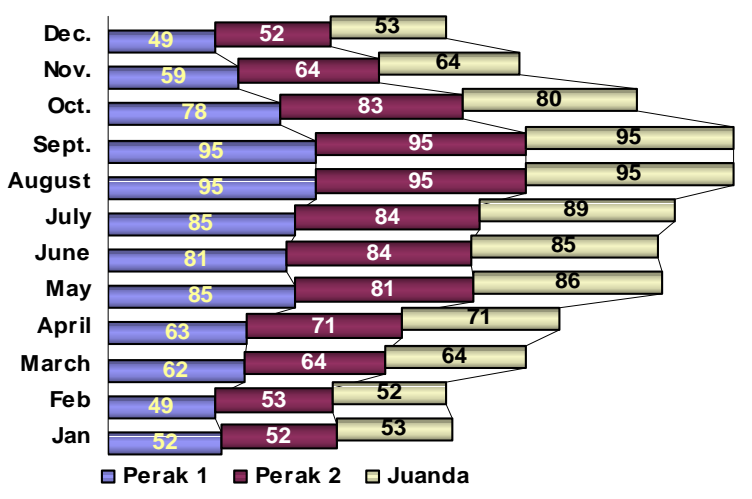

Source: (Surabaya in number 1996 to 2002)

Fig. 1. The monthly average sunshine duration in Surabaya from year 1996 to 2002

Figure 2 shows the weekly average horizontal global solar radiation per hour on October. The highest solar radiation $940 \mathrm{~W} / \mathrm{m}^{2}$ occurs at $11.00 \mathrm{am}$ and, has an average of $558 \mathrm{~W} / \mathrm{m}^{2}$ per day (tested). According to Juniwati (2005), the yearly horizontal global solar radiation predicted with the data of Surabaya sunshine duration and energy software in figure 3 has shown radiation above $500 \mathrm{~W} / \mathrm{m}^{2}$ all around the year. With respect to figure 2 and figure 3 , it is obvious that horizontal global solar radiation either for hot or rainy season is around $500 \mathrm{~W} / \mathrm{m}^{2}$. Therefore, many buildings and dwellings which install horizontal or inclined skylights will experience huge amount of solar heat radiation throughout the days and years.

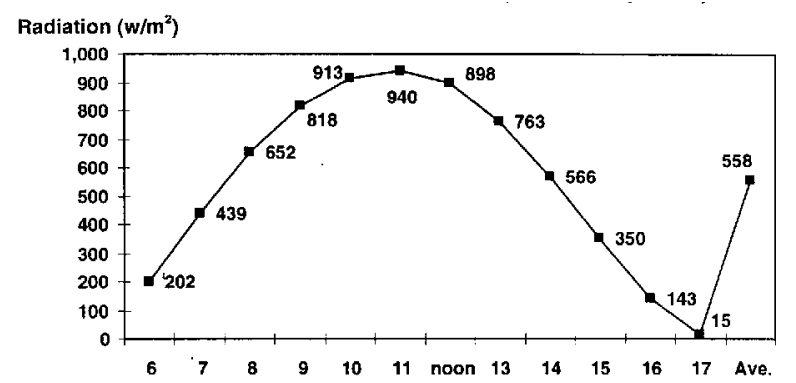

Fig. 2. The weekly ave. horizontal direct and diffuse radiation per hour in Oct. 2006 $\left(\mathrm{W} / \mathrm{m}^{2}\right)$

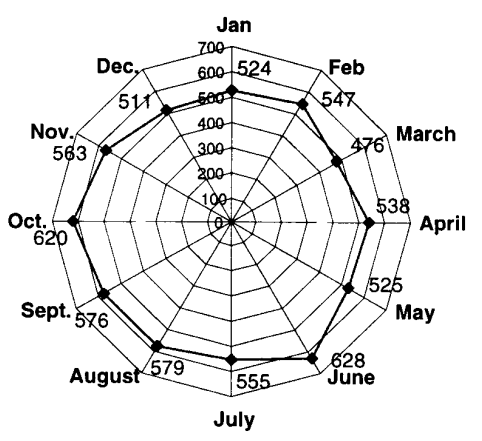

Source: (Juniwati 2005)

Fig.3. The calculated monthly average horizontal direct and diffuse radiation $\left(\mathrm{W} / \mathrm{m}^{2}\right)$

\section{DILEMMA}

Many post-modern architecture buildings and dwellings built now are less designed to respond to the tropical hot humid climate principles and design guidelines in Indonesia especially in Surabaya. Firstly, because of high technologies in various building materials available now, the majority of the designers and architects has more tendency to use these high technology building materials such as glazing - reflective, low-emissivity, and polycarbonate-Lexan, solartuff, twinlite, and more to cover either vertical or horizontal fenestrations than providing conventional shading devices. Secondly, most of the Indonesian people love to have Westernstyle buildings and post-modern dwellings. Ironically, some of Indonesian Architects are just acting as an importer to take European or Latin American skylight and atrium styles without considering the climatic differences. Very few buildings are now equipped with external vertical and horizontal sun shading louvers on vertical windows in Indonesia. And none of the buildings or dwellings which utilize skylights for getting natural daylighting is equipped with external shading devices or louvers over top of the skylights. Other facts that buildings consumed more energy are the ways of air conditioned shopping malls plying with skylights bringing the nature light onto the buildings. First of all, all skylights are installed without considering any shading device. Solar radiation passing through the skylight covers will increase the cooling loads. Secondly, there is no mounting photo-sensors device next to the skylights to decrease the needs of electric lights. Figure 4 gives several illustrations of skylighting atriums at shopping malls and institutions that have been covered with large clear white polycarbonate sheets. According to LIPI on the Development of Electricity and Energy Research Team (1983-1988) in Indonesia, the greatest energy consumption in commercial and office buildings is exhausted on cooling systems - $55 \%$ to $65 \%$, and $12 \%$ to $17 \%$ is lighting systems, then $10 \%$ to $15 \%$ is used for lifts and escalators, lastly $9 \%$ to $13 \%$ is used for other service utilities. So, we, as architects or engineers, have the responsibility not to burden the buildings with extra cooling loads from global solar radiation through the skylights.

\section{INTENTION}

The aquatic polycarbonate skylight device could save significant energy in terms of cooling loads, temperature and in getting hot water in air conditioning buildings. The outcome could provide considerations to designers in designing skylight buildings which have to be related to different climate region strategies. 

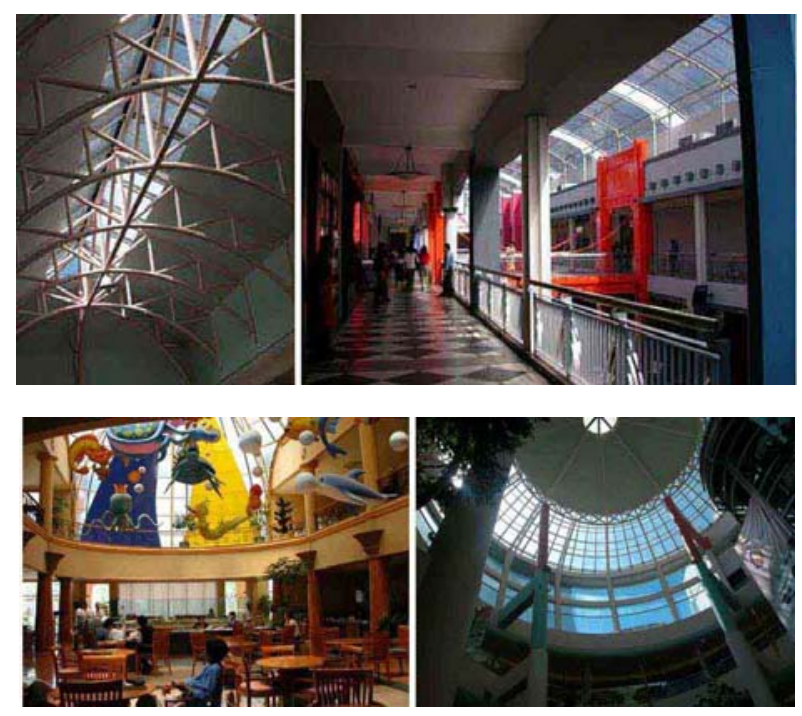

Fig 4: Atrium skylight at shopping malls

\section{METHOD}

\section{Domains of the Research}

Due to the phenomena of many adoptions of Western skylights in buildings over the decade in Indonesia, this research will emphasize on the use of water flushing inside polycarbonate holes as shading and cooling device style for tropical hot humid skylight that may lead to the use of less energy for cooling the interior spaces. In order to avoid increasing of cooling loads caused by the direct sunlight and reflecting the daylight deeply on skylights, the continuous flushing water are needed to carry out the sun heat temperature, and to blocking the direct solar heat radiation as well as to scatter the daylight evenly onto the interior spaces.

The research will look for:

* The energy savings by providing water flushing skylight, expressed in $\mathrm{W} / \mathrm{m}^{2}$.

* The interior illumination after installing water flushing skylight, expressed in lux.

* The water temperature in water polycarbonate skylight as solar hot water, expressed in ${ }^{\circ} \mathrm{C}$.

* The inside-polycarbonate surface temperature, expressed in ${ }^{\circ} \mathrm{C}$.

\section{Materials and Equipment}

Model:

A model is used for testing the room brightness and global radiation to which the direct sun beams are impacted directly to the skylight. The model will have a scale of 1:8 to full size of 4.00 meters long, 4.00 meters wide, and 4.00 meters high $(0.5 \mathrm{~m} \times 0.5 \mathrm{~m}$ $\mathrm{x} 0.5 \mathrm{~m}$ ). The total area is $0.25 \mathrm{~m}^{2}$, and the total volume is $0.125 \mathrm{~m}^{3}$. The dimensions are assumed as one of the single-story atrium shopping mall, or void space in family room at typical houses. The skylight is 0.16 meter wide and 0.16 meter long in 1:8 scales. And the total horizontal skylight area is $0.0256 \mathrm{~m}^{2}$ which is approximately $10 \%$ to the total roof area of $0.25 \mathrm{~m}^{2}$. The walls will be painted white with reflectance factor of around 75\%; the ceiling is white too with reflectance factor of $75 \%$. The floor is plywood style with reflectance factor of $15 \%$.

\section{Skylight Materials:}

Figure 5 shows the skylight material to be tested, is polycarbonate sheet which is the most commonly used in buildings and dwellings in Surabaya for canopies and skylights - 6mm Lexan Thermo Clear from General Electric, with bronze color which has $35 \%$ of light transmission (LT).
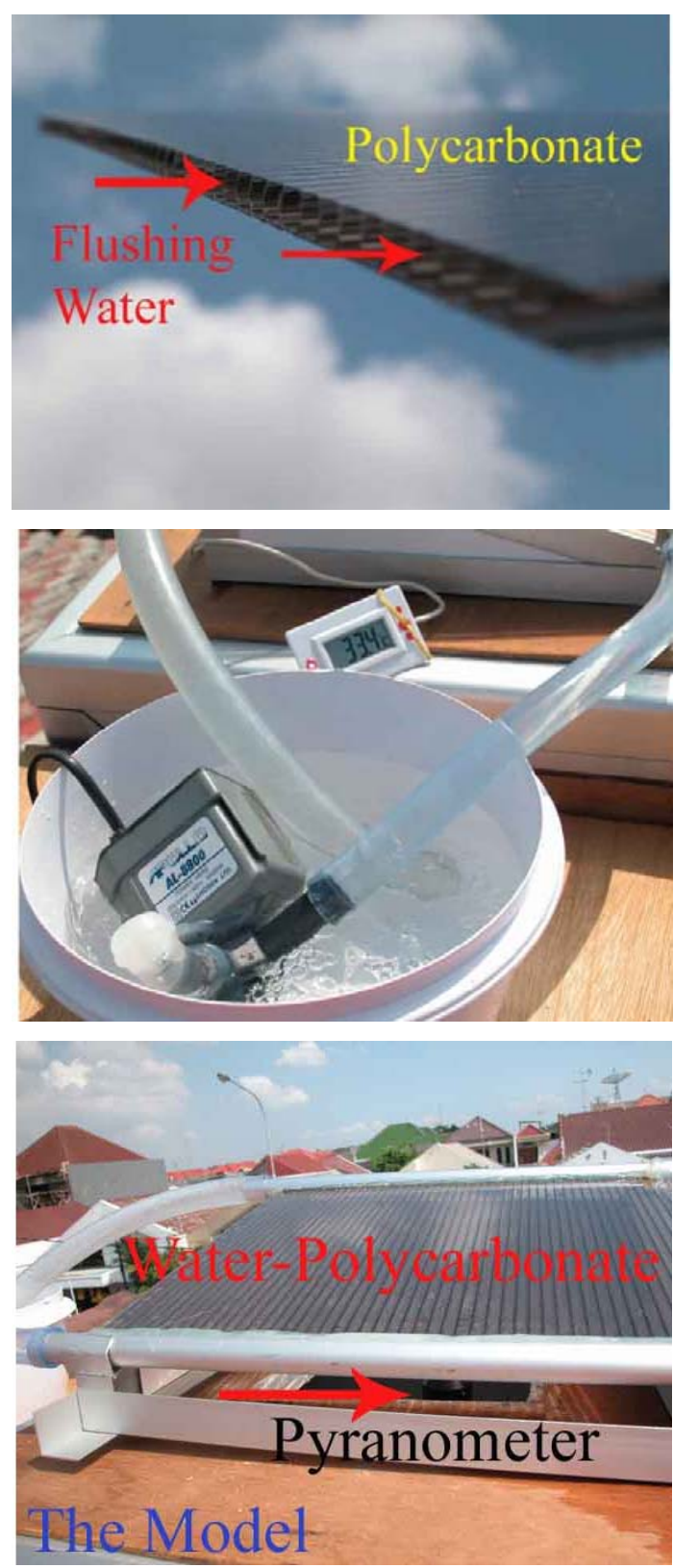

Fig. 5. The water-polycarbonate skylight device and measurement tools 


\section{Measurement Tools}

The equipment used to measure the solar heat radiation is two units of Silicon Pyranometer Smart Sensor from "HOBO" Weather Station Logger with the specification of the measurement ranging from 0 to $1280 \mathrm{~W} / \mathrm{m}^{2}$. Another tool for measuring illumination is The HOBO H8 Light Intensity Sensor Logger with the specification of the measurement ranging from 20 to 6000 lux or 2 to 600 foot-candles. In order to read all the tested data from HOBO equipment, BoxCar Pro4 software is needed. Digital thermometer is used for measuring water temperature, and low energy medium aquarium pump of 60 watts is also used in order to obtain uniform water temperature; the flow rate of water pump is unknown (l/s) (see figure 5).

\section{PROCESS}

The skylight model was tested from 7 am to 4 pm in a day, with the intention to search out how much heat radiation will radiate through the water polycarbonate skylight that is covered with bronze Lexan polycarbonate affecting on the indoor cooling loads and illumination levels. Besides the radiation and indoor illumination levels, the hot water temperatures will be obtained by direct sun beam on the flushing water skylight device.

The model will be tested with flushing the water inside polycarbonate skylight. There are two systems of flushing the water inside the polycarbonate:

a. Closed system or loop circuit

The water inside polycarbonate skylight will be circulated through a pump continuously. This strategy aims to cool polycarbonate surface and sparkle the illumination instead of collecting hot water.

b. Opened system or one-way circuit

The water inside the polycarbonate skylight will be stored in hot water storage, and will be circulated continuously over a day. Figure 6 describes the two systems, the closed circuit is on the left and the opened circuit is on the right side.

\section{RESULTS}

\section{Global Solar Radiation}

It turns out to be that the horizontal polycarbonate skylight with flushing and without flushing the water will receive almost the same amount of direct global solar radiation from the sun every second, minute, and day at the inner space. Table 1 illustrates the global direct and diffuse solar radiation impacts on polycarbonate with and without water flushing in polycarbonate. The solar radiation passing through brown aquatic-polycarbonate skylight with water flushing continuously is surprisingly sometimes higher than polycarbonate skylight without water flushing. The highest radiation value is $392 \mathrm{~W} / \mathrm{m}^{2}$ and occurs at $11 \mathrm{am}$. The performance of water flushing polycarbonate skylight is actually not better than polycarbonate without water flushing in terms of filtering the solar heat radiation. Table 1 points out the solar heat radiation values occurred on both polycarbonates which is nearly matching and occasionally some radiation values occurred hourly on polycarbonate skylight without flushing the water are smaller than the radiation with flushing the water in polycarbonate skylight.
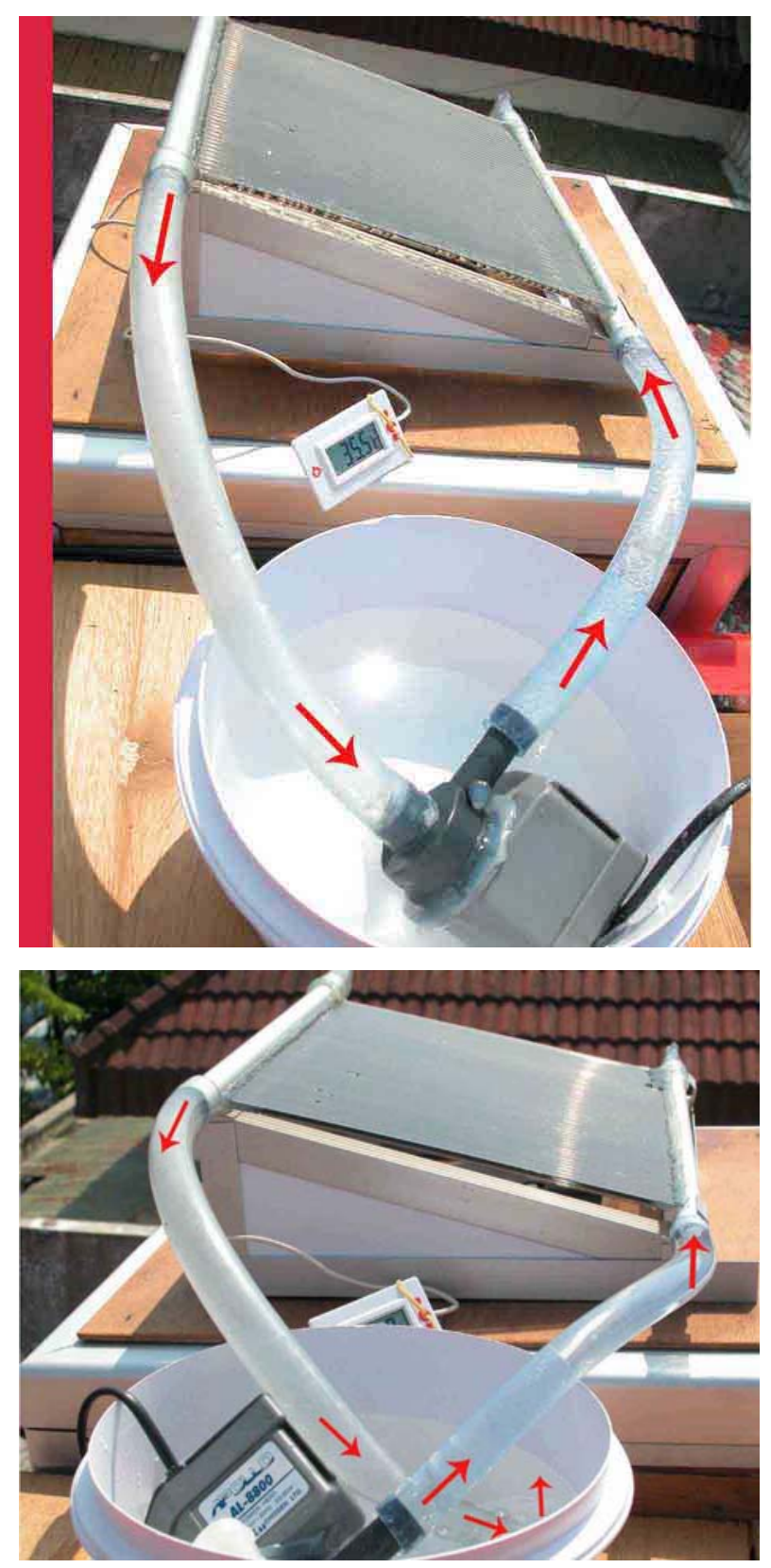

Fig. 6. The water flushing systems on polycarbonate skylight (closed system on the left) 
Table 1. Solar Radiation on Polycarbonate with and without Water Flushing Hourly

\begin{tabular}{cccc}
\hline Time & $\begin{array}{c}\text { Outside } \\
\text { Radiation } \\
\left(\mathrm{W} / \mathrm{m}^{2}\right)\end{array}$ & $\begin{array}{c}\text { Polycarbonate } \\
\text { Skylight } \\
\text { Without Flushing Water } \\
\left(\mathrm{W} / \mathrm{m}^{2}\right)\end{array}$ & $\begin{array}{c}\text { Polycarbonate } \\
\text { Skylight }\end{array}$ \\
\hline $\mathbf{6}$ & 176 & 39 & $\begin{array}{c}\text { Flushing Water } \\
\left(\mathrm{W} / \mathrm{m}^{2}\right)\end{array}$ \\
$\mathbf{7}$ & 379 & 101 & 31 \\
$\mathbf{8}$ & 598 & 199 & 83 \\
$\mathbf{9}$ & 751 & 280 & 226 \\
$\mathbf{1 0}$ & 858 & 371 & 297 \\
$\mathbf{1 1}$ & 876 & 347 & 344 \\
$\mathbf{n o o n}$ & 831 & 332 & 392 \\
$\mathbf{1 3}$ & 696 & 265 & 331 \\
$\mathbf{1 4}$ & 515 & 188 & 293 \\
$\mathbf{1 5}$ & 305 & 90 & 214 \\
$\mathbf{1 6}$ & 119 & 30 & 98 \\
\hline
\end{tabular}

\section{Aqua-Polycarbonate Skylight Temperature}

Two schemes of testing polycarbonate temperature skylight have been performed; one polycarbonate skylight is filled with flushing the water continuously (unknown speed of flow-rate) and other polycarbonate skylight is without filled with flushing water (ordinary horizontal polycarbonate skylight). With the opened circuit-system, the aquatic-polycarbonate skylight has the highest temperature of $39{ }^{\circ} \mathrm{C}$ only, at the same time (hour); the ordinary polycarbonate skylight has the highest temperature of $57{ }^{\circ} \mathrm{C}$ at $1 \mathrm{pm}$. Taking the 17-degree Celsius temperature difference, the indoor air temperature beneath the polycarbonate sheet will raise to affect directly the energy use for room cooling load. Figure7 shows the two polycarbonate temperature differences between the aquatic polycarbonate skylight (circle-dot graph--lower part) and the ordinary polycarbonate skylight (square-dot graphupper part). Both of the skylights expose barely to the direct-heat sun. The two graphs will be lower if there were external louvers installed over the horizontal or incline polycarbonate skylight as shading devices.

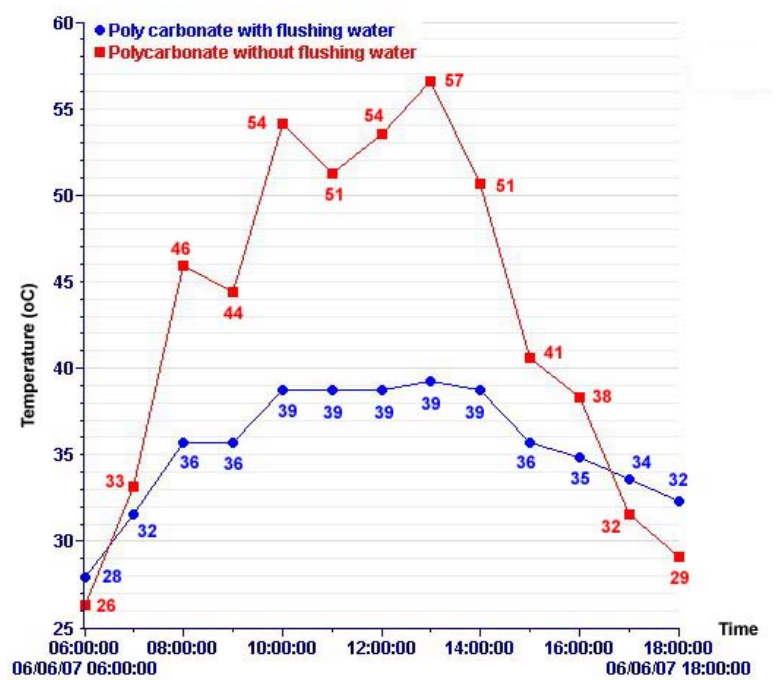

Fig. 7. Polycarbonate temperature in June 2007 (flow rate $1 / \mathrm{s}$ unknown)

\section{Daylight Levels}

On table 2, the daylight levels on polycarbonate skylight without water flushing are higher than aquatic-polycarbonate skylight. The daylight sensors are placed at $75 \mathrm{~cm}$ height above floor level $(9 \mathrm{~cm}$ height on 1:8 scaled) on each model. According to IESNA (1993) the recommended illumination design values for low activity retails and lounge are between 200 lux to 300 lux.

Table 2. The illumination on polycarbonate with and without flushing water hourly in October

\begin{tabular}{ccc}
\hline Time & $\begin{array}{c}\text { Illumination on } \\
\text { Polycarbonate } \\
\text { Without Flushing Water } \\
\text { ( Lux ) }\end{array}$ & $\begin{array}{c}\text { Illumination on } \\
\text { Polycarbonate } \\
\text { With Flushing Water } \\
\text { ( Lux ) }\end{array}$ \\
\hline $\mathbf{6}$ & 250 & 250 \\
$\mathbf{7}$ & 590 & 670 \\
$\mathbf{8}$ & 1190 & 1190 \\
$\mathbf{9}$ & 1950 & 1830 \\
$\mathbf{1 0}$ & 4950 & 3310 \\
$\mathbf{1 1}$ & 6850 & 6790 \\
$\mathbf{n o o n}$ & 5380 & 4000 \\
$\mathbf{1 3}$ & 2220 & 2030 \\
$\mathbf{1 4}$ & 1360 & 1360 \\
$\mathbf{1 5}$ & 690 & 610 \\
$\mathbf{1 6}$ & 250 & 250 \\
\hline
\end{tabular}

It seems that all illumination values fulfill the recommended design values starting from 6 am to 5 pm (250 lux to 250 lux), even the tested model will experience saturated daylight levels for seven hours (8 am to $2 \mathrm{pm}$ )-over a thousand Lux. A room is supposed to be saturated with daylight when the illuminance levels from daylight meet or surpass the illuminance design target for that space.

\section{Solar Hot Water Temperature}

Figure 8 shows the results of the hot water temperature with the opened circuit system on flushing water-polycarbonate skylight conjunction with filtering solar radiation purposes. Fortunately, it could get the highest average hot water temperature of $42.2 \mathrm{C}^{\circ}$ at noon time. The water temperature has risen slowly after $11 \mathrm{am}$, and after that the temperature will easily drop degree by degree. This phenomenon could be caused by windy situation on the roof-top skylight. The breeze has an effect on cooling down slightly the surface of the warm water-polycarbonate skylight. We have to find out another way to protect the warm water temperature loss by wind conduction at water flushing polycarbonate. Maybe a tint glass box covering the water-polycarbonate skylight is the best way to provide greenhouse affect. 
Temperature $\left(C^{\circ}\right)$

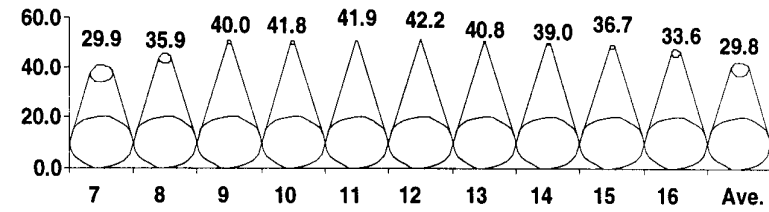

Fig. 8. Average hot water temperature in the water-polycarbonate skylight per day in October

\section{Energy-saving Domains}

After testing all systems, there are significant energy savings both on cooling down the inner surface temperature of the polycarbonate sheet skylight by applying water-polycarbonate skylight then conventional polycarbonate skylight, and on getting solar hot water. Besides energy saving domains, the sustainable clean environmental electricity on generating daylight levels has been established by the aquatic-skylight. The only weakness side is the direct solar radiation. The aquatic polycarbonate skylight will remain transporting the amount of direct solar radiation to the inner room. Each system has been proven to have the strong and less strong sides which work together optimally for reducing the needs of extra energies - cooling loads, lighting loads, heating loads on hot water as well as cooling the temperature loads.

\section{CONCLUSION}

Although the aquatic polycarbonate skylight actually could not cut off significantly the direct solar heat radiation passing through a piece of waterpolycarbonate sheet, it did prove nicely to reduce the surface temperature and to collect warm water satisfactorily. Furthermore, the flushing water in polycarbonate skylight did demonstrate not only significantly scattering the direct sun beam as diffuse daylight but also silently and efficiently reducing the polycarbonate inner surface temperature. Further research is needed to figure out the prevention of getting yeast or mold inside the polycarbonate holes. The water flow-rate on different speeds $(\mathrm{l} / \mathrm{s})$ which will affect the sheet temperature, is requires to be researched either.

\section{Acknowledgement}

This research is sponsored by the department of Architecture of the Petra Christian University. My thanks are extended to who provided encouragement and useful advice throughout this research, as well as to the anonymous reviewers of this paper.

\section{REFERENCES}

Illuminating Engineering Society of North America, 1993, Lighting Handbook: Reference and Application $8^{\text {th }}$ ed., IES, New York..

Iqbal, Muhammad, 1983, An Introduction to Solar Radiation, Academic Press, New York..

Juniwati, Anik, 2005, The Influence of High-rise Building Façade on Warm-humid Climate, Master Thesis, Sepuluh November Institute of Technology.

LIPI report, 1983-1988, Electricity and Energy Used in Commercial and Office Buildings in Indonesia.

Kondratyev, K. Ya, 1994, Radiation in the Atmosphere, Leningrad University, Leningrad, USSR.

Ruck, Nancy, 2000, Daylight in Buildings: A Source Book on daylighting Systems and Components, International Energy Agency, New York.

Roaf, Susan, Mary Hancock, 1992, Energy Efficient Building: A Design Guide, Blackwell Scientific Publications, London.

Skylighting Guidelines, 1998, Heschong Mahone Group

Stein, Benjamin, John S. Reynolds and William J. McGuinness, 1986, Mechanical and Electrical Equipment for Buildings, John Wiley \& Sons, New York.

Szokolay, S.V., 1992, Architecture and Climate Change, RAIA Education Division, Australia.

Tips for Daylighting with Windows, 2002, Ernest Orlando Lawrence Berkeley National Laboratory, Berkely. 